\title{
Biotic Transitions in Global Marine Diversity
}

\author{
Arnold I. Miller
}

Long-term transitions in the composition of Earth's marine biota during the Phanerozoic have historically been explained in two different ways. One view is that they were mediated through biotic interactions among organisms played out over geologic time. The other is that mass extinctions transcended any such interactions and governed diversity over the long term by resetting the relative diversities of higher taxa. However, a growing body of evidence suggests that macroevolutionary processes effecting biotic transitions during background times were not fundamentally different from those operating during mass extinctions. Physical perturbations at many geographic scales combined to produce the long-term trajectory of Phanerozoic diversity.

$\mathbf{P}$ hanerozoic trends in global marine faunal diversity continue to be of central concern to researchers interested in the history of life. After the establishment of metazoans in the Vendian and Cambrian, Phanerozoic patterns $(1,2)$ exhibited three easily observed characteristics (Fig. 1A): (i) intervals of increasing diversity focused mainly in the early Paleozoic and the postPaleozoic, (ii) intervals of decreased diversity and rebound associated with mass extinctions, and (iii) broad transitions in dominance among higher taxa. These attributes, and possible relationships among them, have led to two different theories $(3,4)$ to explain the major features of Phanerozoic diversification. One theory holds that mass extinctions constitute a distinct class of phenomena that transcended ongoing evolutionary patterns and processes operating at other times and governed long-term, global biotic transitions through wholesale removal of incumbents ( 5 , $6)$. The other theory is that mass extinctions played only minor roles in governing longterm diversification that was instead linked to biotic interactions over extended intervals of geologic time $(4,7)$.

However, recent work on several seemingly disparate topics points to a third possibility: that diversification represents the summed accumulation of physically mediated transitions that took place rapidly in geographically limited venues around the world. Despite the abruptness of faunal changes locally, the apparent rates of these transitions were damped in global diversity transitions because their timing varied from venue to venue around the world, depending on the local or regional onset of physical conditions that induced the transitions. In this context, mass extinctions, although capable of mediating diversity over the long term, constitute

The author is in the Department of Geology, University of Cincinnati, Post Office Box 210013, Cincinnati, OH 45221-0013, USA. E-mail: arnold.miller@uc.edu the largest end members of a continuum of physical mechanisms that induced appreciable, rapid biotic turnover on geologic time scales $(8)$. Here I provide a theoretical rationale for this third alternative and review evidence for episodic biological turnover on local and regional scales, linked to physical

\section{Phanerozoic Global Diversity Trends}

For nearly two decades, the diversity trajectory depicted in Fig. 1A, and the data used to construct it (9), have provided the basis for evaluating changes in total diversity throughout the Phanerozoic and the taxonomic transitions that accompanied them (10). Although questions remain concerning the possible roles of sampling artifacts in mediating the observed trajectory (11), the broad Phanerozoic pattern has proven impervious both to taxonomic problems (12) and to different methods of assembling the relevant data (13, 14) (Fig. 1B)

Despite the robustness of the diversity pattern, interpreting it has been more problematic. One fruitful approach has involved mathematical modeling of diversity dynamics. Using simple, plausible assumptions, the Phanerozoic diversity trajectory and transitions among the Cambrian, Paleozoic, and Modern evolutionary faunas (Fig. 1A) (10) have been simulated at the family level ( 7 , 15 ). On average, the Cambrian fauna exhibited higher familial origination and extinction rates than did the Paleozoic fauna, which in turn exhibited higher rates than did the Modern fauna. Each of three interacting groups was therefore assigned a set of parameters, including characteristic initial rates of familial origination and extinction, paralleling, in a relative sense, empirical observations of the evolutionary faunas. The outcome of the model (Fig. 1E), when run through increments intended to simulate Phanerozoic time, was similar to the observed Phanerozoic trajectory (Fig. 1A). environmental transitions.
By design, the diversity trajectories of each of the three simulated groups were governed mainly by their numerical interactions with the other two groups, with numerically mediated limits to total diversity achieved or approached in simulated intervals corresponding to the Late Cambrian, mid- to late Paleozoic, and post-Paleozoic. Rapid diversity decreases that were incorporated to simulate the five major mass extinctions of the Phanerozoic had little effect on the long-term trajectory of the simulation (Fig. 1E): After the extinctions, the three groups assumed diversification pathways that they occupied before the events.

Benton (16) argued, as an alternative, that the entire Phanerozoic trajectory can be viewed as a single exponential diversification. Despite this assertion, the actual pertaxon diversification trajectory varied throughout the Phanerozoic and did not parallel the best fit exponential path (Fig. 1C). Courtillot and Gaudemer (17) argued that the overall diversity trajectory could instead be approximated by a composite of four logistic curves constructed for successive portions of the Phanerozoic demarcated by mass extinctions, each with unique diversification parameters and carrying capacities (Fig. 1D). In contrast to Sepkoski $(7,15)$, however, Courtillot and Gaudemer suggested that simple, noninteractive, logistic diversification, interrupted and reset by mass extinctions, best matched the Phanerozoic patterns.

The most compelling evidence that a mass extinction can fundamentally alter global marine diversity is provided by the Late Permian event, which marks an abrupt change in the relative global diversities of the Paleozoic and Modern faunas (Fig. 1A). Recognizing this transition, Gould $(5,6)$ proposed that mass extinctions played major roles in governing Phanerozoic diversity, but that, in doing so, they constituted a distinct "tier" of macroevolutionary phenomena capable of resetting diversity pathways that developed during intervals between mass extinctions.

One of the strengths of Sepkoski's interactive model is its incorporation of an empirical reality - the declining turnover rates exhibited by successive evolutionary faunas. However, this transition could have occurred without such interactions (18). Branching theory predicts a direct relation between the rates of origination and extinction exhibited by a clade, and the clade's propensity to exhibit dramatic diversity changes through 


\section{SCIENCE'S COMPASS}

time (that is, its volatility). Gilinsky (19) found empirical support for this prediction. A clade with a higher turnover rate is more volatile and is therefore more likely to become extinct as a result of stochastic fluctuations in diversity. Thus, in a system in which clades exhibit relative degrees of volatility that parallel their respective turnover rates through time, more volatile clades should become extinct, while less volatile clades survive. By this logic, clades composing the high-turnover Cambrian fauna were more susceptible to extinction than those composing the Paleozoic fauna, which were more extinction-prone than members of the Modern fauna. There is evidence of this differential susceptibility during mass ex-
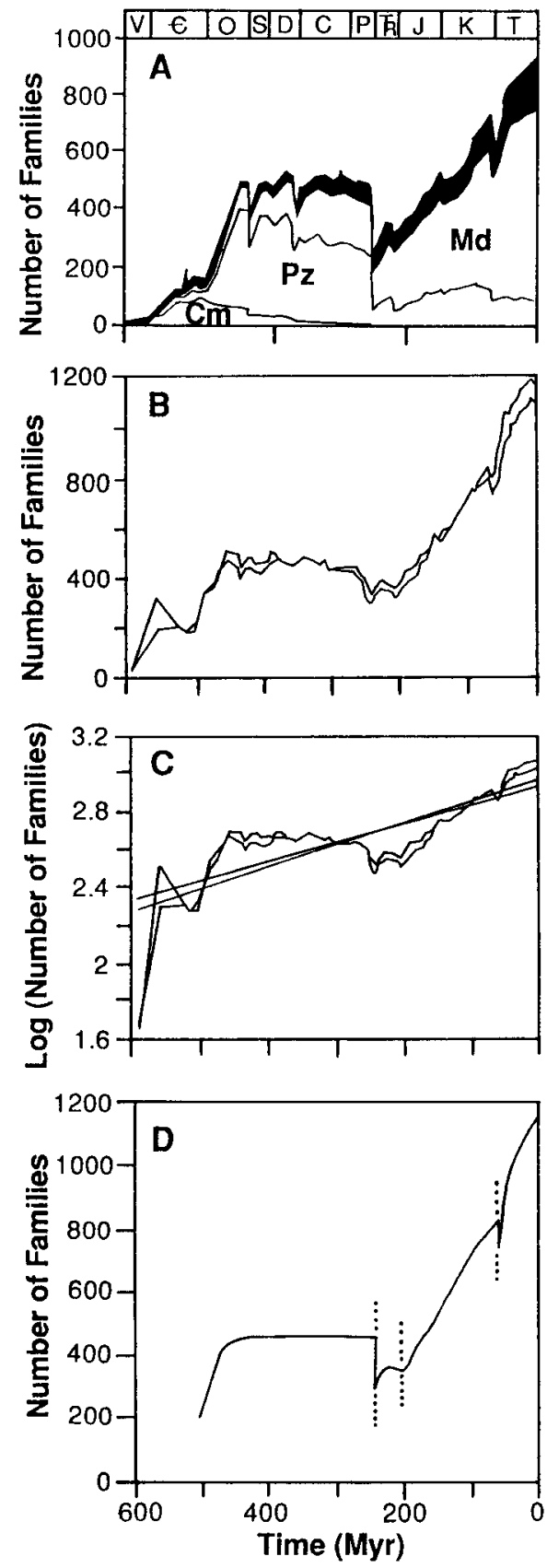

tinctions $(7,20)$, which suggests that the Phanerozoic transitions among evolutionary faunas are governed by the differential responses of their component taxa to extinction events.

Finally, even by the broad measures used to characterize taxa on a global scale, evolutionary faunas were not the internally uniform and individually distinct entities that one might expect as a basis for the interactive model described earlier. For example, comparative familial extinction and origination probabilities exhibited by orders of trilobites - the major taxonomic contributors to the Cambrian fauna-varied by as much as a factor of 4 (19). Indeed, Ordovician trilobites might be appropriately viewed as comprising

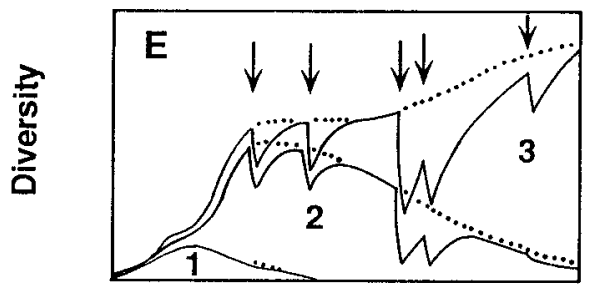

Fig. 1. Several illustrations and interpretations of Phanerozoic trends in global marine diversity. (A) Sepkoski's depiction of familial diversity including transitions among the three Phanerozoic evolutionary faunas (10): the Cambrian fauna $(\mathrm{Cm})$, the Paleozoic fauna $(\mathrm{Pz})$, and the Modern fauna (Md). The darkened region indicates poorly preserved families. V, Vendian; $\epsilon$, Cambrian; O, Ordovician; S, Silurian; D, Devonian; C, Carboniferous; P, Permian; TR, Triassic; J, Jurassic; K, Cretaceous; and T, Tertiary. This figure is modified from figure 1.2 of (2). (B) Benton's depiction of familial diversity. The two curves are maximum and minimum estimates of diversity, based on inclusion and exclusion of taxa that could not be assigned to a stratigraphic stage or to the marine realm. This figure is modified from figure $1 \mathrm{C}$ of (16). (C) A semilogarithmic graph of the curves from (B). The superimposed diagonal lines are best fit exponential trajectories for the two curves. This figure is modified from figure $2 C$ of (16). (D) A model of Phanerozoic diversity from the Ordovician to the Recent, based on a composite of four logistic curves constructed for successive portions of the Phanerozoic demarcated by mass extinctions (dotted lines). Each of the four curves had unique diversification parameters. This figure is after figure 1 of (17). (E) Sepkoski's three-phase coupled logistic model of Phanerozoic diversity, illustrating the modeled trajectories of the Cambrian (1), Paleozoic (2), and Modern (3) faunas. The five major mass extinctions of the Phanerozoic were incorporated (arrows) at times, and with magnitudes, corresponding to their occurrences in the empirical record, as depicted in (A). The dotted lines depict the trajectories of the three faunas in a simulation without mass extinctions. This figure is modified from figure $8 \mathrm{C}$ of (7). two distinct macroevolutionary biotas (21). On a wider taxonomic spectrum, average pergenus origination rates of classes comprising the Cambrian and Paleozoic faunas varied by two orders of magnitude. Further, there was considerable overlap among the three faunas in the per-genus origination rates of their constituent classes (22).

\section{Dissecting Global Diversity: Toward a Unified View of Transitions}

Mass extinctions appear to be nearly instantaneous in global-scale diversity compilations, but major diversity increases appear to be more protracted (Fig. 1). When viewed at the synoptic global scale, it is difficult to avoid the impression that the protracted increases were caused by globalscale processes that were a distinctly different class of phenomena from those mediating mass extinctions.

If the rates of biotic transition depicted in global-scale compilations were linked to processes that operated around the world, it follows that rates at the local and regional levels should be manifestations of those at the global level. However, recent analyses of the Ordovician Radiation (23) and the recovery from the Cretaceous/Tertiary $(\mathrm{K} / \mathrm{T})$ mass extinction (24) indicate otherwise (25). The timing and taxonomic attributes of Ordovician diversity transitions varied markedly from region to region, depending on the onset of physical conditions locally or regionally that served to decimate incumbent organisms and foment the immigration and diversification of taxa that were not previously diverse or abundant there $(23,26)$. Locally, major biotic transitions took place rapidly $(26,27)$, but because the timing of these transitions varied from region to region, global-scale compilations of Ordovician diversity exhibit a more protracted pattern (25). The global pattern reflects neither the rate at which the transitions actually took place in many individual regions nor the substantial regional variability in the taxonomic attributes of the transitions (25). The recovery of molluscs from the $\mathrm{K} / \mathrm{T}$ extinction in the Gulf Coast region of North America, which was once thought to indicate a global-scale response to the decimation, has been shown to differ from that observed in other regions (24).

The episodicity of diversity transitions on local and regional scales transcends the Ordovician and early Tertiary. In recent years, local and regional studies of marine faunal patterns have converged on a similar themethat biotic turnover occurred episodically through investigated stratigraphic intervals. There were comparatively broad intervals with little net turnover, punctuated by narrower intervals in which many taxa either emigrated or became extinct and were replaced largely by a roster of taxa that either 


\section{SCIENCE'S COMPASS}

originated in the area or immigrated into it (28). Although aspects of this general pattern have proven to be variable and controversial (29), episodicity appears to be a general feature of regional stratigraphic packages. The rate of turnover may be accentuated by gaps in the stratigraphic record (30), but the pattern remains even when these and other problems of preservation and sampling are accounted for (31).

Moreover, in cases where these rapid transitions have been related to physical stratigraphic patterns, including the Siluro-Devonian of the Appalachian Basin (32) and the Middle and Upper Ordovician of the eastern United States (31), there is a direct correspondence between biotic turnover and physical transitions. In some cases, these were regional manifestations of global perturbations, and the turnover can be correlated to other such episodes worldwide. In many instances, however, the physical transitions and concomitant faunal responses, which included immigration/emigration and origination/extinction, were strictly regional in scope and have not been correlated beyond the study area.

Thus, major faunal transitions in globalscale compilations, which seem to have transpired over protracted intervals of geologic time, took place far more rapidly and episodically when evaluated regionally or locally. The transitions only appear gradual on a global scale because of variations in their timing from venue to venue. This eliminates the apparent dichotomy, on a global scale, between mass extinctions and the protracted intervals that they appear to punctuate. The processes that produced major mass extinctions simply represented the largest and most globally extensive of a spectrum of perturbations that produced episodic biotic transitions.

It has been demonstrated that broad geographic ranges and related attributes enhanced species survival during background extinction intervals but not during mass extinctions (33). However, these differences might reflect the global reach of mass extinctions versus the regional focus of background extinction episodes, rather than mechanistic differences among mass and background extinction regimes. In a regional extinction, a species should persist if its geographic range extends beyond the affected area, but no such refuge is available if the effect is global, as it is during most mass extinctions.

\section{Reinterpreting Biotic Trends: Enhanced Roles for Physical Transitions}

Several paleobiologists have evaluated longterm, global biotic transitions in light of biotic interactions taking place in the present day. For example, Thayer (34) analyzed the decline of immobile suspension feeders living on soft substrates (ISOSS) starting in the mid- to late Paleozoic and demonstrated that it coincided with a diversification of depositfeeding organisms that were capable of extensive bioturbation ("biological bulldozers"). In the present day, such bioturbation can inhibit or exclude suspension feeders in benthic habitats (35), and Thayer suggested that the demise of ISOSS resulted from the diversification of biological bulldozers that undermined sediments on which ISOSS lived.

However, the activity of biological bulldozers in present-day habitats can be inhibited where there is a well-established incumbent biota that is capable of consolidating the substrate (35); the intervention of perturbations such as storms may be required to remove incumbents before infiltration by deposit feeders. In a paleoecological context, biological bulldozers might only have become established regionally after ISOSS had already been decimated because of major physical transitions. During the Late Devonian, an increase in tectonic activity, including the Acadian Orogeny in North America, produced a shift to siliciclastic-rich muddy substrates that were favorable to biological bulldozers.

Vermeij (36) cataloged numerous instances in which taxa exhibited morphologic changes through geologic time in response to the diversification of others that interacted with and, in some instances, preyed on them. These transitions were manifested as declines in the richness of taxa exhibiting morphologic attributes that rendered them vulnerable to escalating biological conditions and to increases among taxa with attributes better suited to these changing circumstances. Although the case for these kinds of transitions over the sweep of the Phanerozoic is difficult to deny, the manner in which they transpired over shorter intervals is less certain. There is little evidence of gradual escalation through stratigraphic intervals at local or regional levels (28). The introduction of escalated forms appears to have occurred episodically, in concert with the broader class of changes in taxonomic composition discussed earlier, which suggests a role for physical mediation.

Another class of biotic transitions that has been extensively investigated is the "onshoreoffshore" pattern of benthic marine diversification (37). Among other things, Jablonski and Bottjer (38) demonstrated that post-Paleozoic orders originated overwhelmingly in near-shore environments. It has generally been accepted that some aspect of living near the shore either enhanced the likelihood that newly diversified forms would be particularly novel (39) or enhanced rates of diversification, thereby increasing the probability that novel groups would originate or diversify in such settings (40).

However, Jacobs and Lindberg (41) sug- gested a role for physical transitions in producing the ordinal origination pattern. They showed that there was a confinement of ordinal origination to near-shore settings before the Cenomanian-Turonian stage boundary of the Cretaceous Period but not thereafter. As Jacobs and Lindberg also documented, bottom conditions in offshore settings were commonly anoxic or dysoxic before the boundary, but these conditions ameliorated later, enhancing the possibility of offshore occupation and thus of ordinal origination.

\section{Discussion and Prospects}

Gould (6) argued that mass extinctions constitute an overarching third tier in a hierarchy of evolutionary processes, in which patterns and transitions associated with one tier can be undone by processes at a higher tier. In this hierarchy, the first tier consists of gradual evolutionary change through ecological time and the second represents the level at which more profound change associated with speciation is focused. More recently, Bennett (42) proposed the addition of a tier between Gould's first and second tiers, being a distinct level at which evolutionary stasis is expressed: everpresent climatic oscillations cause repeated disruptions in relationships among species in biotic assemblages and continuous reshuffling of their individual geographic ranges, disrupting changes that might otherwise accumulate at the first tier.

The topics discussed here do not address the reality or the discreteness of Gould's first and second tiers, nor that of Bennett's first, second, and third tiers. They do, however, suggest that a hierarchical break is not warranted between mass extinctions at the highest tier and background speciation at the next highest tier. Instead, perturbations that produced mass extinctions were the most extensive end members of a continuum of physically induced transitions that were capable of producing episodic biotic transitions, including origination and extinction, on scales ranging from regional to global. Individual events of speciation that might best characterize Gould's second and Bennett's third tier constitute the other, highly localized, end members of the continuum.

Local and regional biotic transitions related to physical stratigraphic patterns $(26$, $27,31,32)$ are examples of the data that are available to evaluate the relationship among biotic diversification patterns at different geographic scales. As this database continues to grow, two kinds of tests will be useful in determining the significance of physical transitions in mediating diversity. First, during times of changing global diversity over extended intervals (for example, the rise of biological bulldozers during the mid- to late Paleozoic), local changes in 
the biotic compositions of major taxa or ecological groups should be mapped with respect to physical stratigraphic patterns. If biotic transitions are controlled primarily by local physical transitions, then major changes in taxonomic or ecological compositions of local assemblages should not take place continuously over an interval under study but should be concentrated in intervals during which the physical setting undergoes a significant net change. Second, the biotic compositions of individual classes of paleoenvironments from region to region around the world (for example, offshore siliciclastic muds) can be evaluated through critical stratigraphic intervals. If biological transitions during an interval were controlled locally by the changing availability of particular environmental conditions, then elements of the incoming biota should predate the critical interval in habitats outside a study region where the appropriate environmental suite predominates, before their establishment in the region. Similarly, elements of the outgoing biota could persist beyond the critical interval in other regions if the appropriate environmental conditions persisted. In such instances, some of these elements might reappear in a region if the physical setting reverted to a former state. Just such a pattern of departure and subsequent reappearance was recognized in Middle and Upper Ordovician strata of eastern midcontinental North America (26).

\section{References and Notes}

1. J. J. Sepkoski Jr., Paleobiology 7, 36 (1981).

2. J. Paleontol. 71, 539 (1997).

3. S. C. Morris, Philos. Trans. R. Soc. London Ser. B 353 327 (1998)

4. J. C. Briggs, BioScience 48, 389 (1998).

5. S. J. Gould and C. B. Calloway, Paleobiology 6, 383 (1980).

6. S. J. Gould, ibid. 11, 2 (1985)

7. J. J. Sepkoski Jr., ibid. 10, 246 (1984).
8. D. M. Raup, ibid. 17, 37 (1991).

9. J. J. Sepkoski Jr., Milw. Public Mus. Contrib. Biol. Geol. 51, 1 (1982); ibid. 83, 1 (1992).

10. Sepkoski (1) argued that Phanerozoic marine diversity can be divided into three groups, called evolutionary faunas, each containing class- or ordinal-level taxa with comparable familial turnover rates and similar Phanerozoic diversity trajectories. The Cambrian fauna (such as trilobites and inarticulate brachiopods) dominated Cambrian seas, the Paleozoic fauna (such as articulate brachiopods, stalked crinoids, tabulate and rugose corals, and stenolaemate bryozoans) predominated during the rest of the Paleozoic, and the Modern fauna (such as bivalve and gastropod molluscs, echinoids, and gymnolaemate bryozoans) exhibited its greatest prominence in the post-Paleozoic.

11. D. M. Raup, Paleobiology 2, 289(1976); A. I. Miller and M. Foote, ibid. 22, 304 (1996).

12. J. J. Sepkoski Jr., Paleobiology 19, 43 (1993); and D. C. Kendrick, ibid., p. 168.

13. J. J. Sepkoski Jr., R. K. Bambach, D. M. Raup, J. W. Valentine, Nature 293, 435 (1981).

14. M. J. Benton, Ed., The Fossil Record 2 (Chapman \& Hall, London, 1993). The data in this volume, which were used in the construction of Fig. 1B, were assembled by a diverse set of specialists using methods and sources that differed somewhat from those used by Sepkoski in the construction of his compendia (9).

15. See Sepkoski (7) and his earlier papers on logistic modeling of global diversity [ J. J. Sepkoski Jr., Paleobiology 4 223 (1978); ibid. 5, 222 (1979)] for a full discussion and justification of the use of logistic models in evaluating the history of global biodiversity.

16. M. J. Benton, Science 268, 52 (1995).

17. V. Courtillot and Y. Gaudemer, Nature 381, 146 (1996).

18. J. W. Valentine, Palaeogeogr. Palaeoclimatol. Palaeoecol. 75, 137 (1989).

19. N. L. Gilinsky, Paleobiology 20, 445 (1994).

20. S. M. Stanley, Macroevolution: Pattern and Process (Freeman, San Francisco, CA, 1979).

21. J. M. Adrain, R. A. Fortey, S. R. Westrop, Science $\mathbf{2 8 0}$ 1922 (1998)

22. J. J. Sepkoski Jr., Philos. Trans. R. Soc. London Ser. B 353, 315 (1998).

23. A. I. Miller, Annu. Rev. Ecol. Syst. 28, 85 (1997); Geobios Mem. Spec. 20, 397 (1997).

24. D. Jablonski, Science 279, 1327 (1998).

25. D. H. Erwin, ibid., p. 1324. The figure therein, derived from my research, illustrates the extent to which the Ordovician genus origination rate of bivalve molluscs varied from continent to continent around the world.

26. M. E. Patzkowsky and S. M. Holland, Geology 21, 19 (1993).

27. M. L. Droser, R. A. Fortey, X. Li, Am. Sci. 84, 122 (1996).
28. C. E. Brett, L. C. Ivany, K. M. Schopf, Palaeogeogr. Palaeoclimatol. Palaeoecol. 127, 1 (1996).

29. L. C. Ivany, ibid., p. 279; A. I. Miller, Paleobiology 23, 155 (1997); R. A. Kerr, Science 278, 576 (1997).

30. S. M. Holland, Palaeogeog. Palaeoclimatol. Palaeoecol. 127, 147 (1996).

31. M. E. Patzkowsky and S. M. Holland, Paleobiology 23, 420 (1997)

32. C. E. Brett and G. C. Baird, in New Approaches to Speciation in the Fossil Record, D. H. Erwin and R. L. Anstey, Eds. (Columbia Univ. Press, New York, 1995), pp. 285-315.

33. D. Jablonski, Science 231, 129 (1986).

34. C. W. Thayer, ibid. 203, 458 (1979); in Biotic Interactions in Recent and Fossil Benthic Communities, M. J. S. Tevesz and P. L. McCall, Eds. (Plenum, New York, 1983), pp. 479-625.

35. D. C. Rhoads and D. K. Young, J. Mar. Sci. 28, 150 (1970).

36. G. J. Vermeij, Paleobiology 3, 245 (1977); Evolution and Escalation (Princeton Univ. Press, Princeton, NJ, 1987)

37. D. Jablonski, J. J. Sepkoski Jr., D. J. Bottjer, P. M. Sheehan, Science 222, 1123 (1983).

38. D. Jablonski and D. J. Bottjer, in Evolutionary Innovations, M. H. Nitecki, Ed. (Univ. of Chicago Press, Chicago, IL, 1990), pp. 253-288; Science 252, 1831 (1991).

39. __ in Biotic Interactions in Recent and Fossil Benthic Communities, M. J. S. Tevesz and P. L. McCall, Eds. (Plenum, New York, 1983), pp. 747-812; in Causes of Evolution: A Paleontological Perspective, R. M. Ross and W. D. Allmon, Eds. (Univ. of Chicago Press, Chicago, IL, 1990), pp. 21-75.

40. J. J. Sepkoski Jr., Paleobiology 17, 58 (1991).

41. D. K. Jacobs and D. R. Lindberg, Proc. Natl. Acad. Sci. U.S.A 95, 9396 (1998). There were methodological differences in Jacobs and Lindberg's treatment of the ordinal origination data relative to that of Jablonski and Bottjer. However, Jacobs and Lindberg noted that their results were robust to several alternative treatments, including deemphasis of poorly preserved orders, and to placement of the onshore-offshore boundary in the same position as that of Jablonski and Bottjer.

42. K. D. Bennett, Paleobiology 16, 11 (1990); Evolution and Ecology: The Pace of Life (Cambridge Univ. Press, Cambridge, 1997).

43. I thank M. Foote, D. H. Erwin, S. M. Holland, D. Jablonski, and D. W. McShea for reading and commenting on an earlier version of the manuscript and L. Trump for drafting Fig. 1. My research on global diversity and the Ordovician Radiation has been facilitated through support from NASA's Program in Exobiology (grants NAGW-3307 and NAG5-6946).

\section{Tired of waiting for Godot?}

NEW! Science Online's Content Alert Service: Now you can get instant summaries of science news and research findings with Science's Content Alert Service. This free enhancement to your Science Online subscription delivers e-mail summaries of the latest news and research articles published each Friday in Science - instantly. To sign up for the Content Alert service, go to Science Online and end the wait.

\section{Science}

For more information about Content Alerts go to www.sciencemag.org. Click on Subscription button, then click on Content Alert button. 